\title{
Optimal blood pressure control for patients after thoracic endovascular aortic repair of type B aortic dissection
}

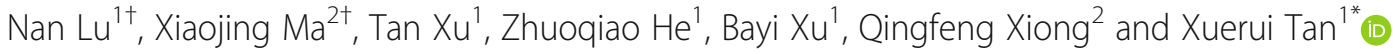

\begin{abstract}
Background: Guidelines recommend tight systolic blood pressure (SBP) control for favorable outcomes of type B aortic dissection (BAD) but are still limited by the optimal cut-off value of SBP. The purpose of this study was to evaluate the optimal cut-off value of SBP in BAD patients after thoracic endovascular aortic repair (TEVAR).

Methods: From January 2011 to April 2017, 269 consecutive patients with BAD after TEVAR were included in the study. All patients were followed up according to a strict follow-up protocol. Cox regression analysis was used to examine the association between SBP at discharge and 90-day aortic related adverse events (ARAE).

Results: All 269 patients completed 90 days of follow-up, and the unadjusted ARAE-free rates at 90-day was $95.1 \pm$ 1.3\%. The cut-off value of SBP at discharge identified by receiver operator curve was $130 \mathrm{mmHg}$ for 90-day ARAE. In multivariable models, binary SBP at discharge was significant associated with 90-day ARAE (HR 3.780; 95\% Cl 1.23611.556; $p=0.020$ ). Hybrid operation (OR 2.046; 95\% Cl 1.015-4.122; $p=0.045$ ) and insertion of $\geq 2$ stents (OR 2.950; $95 \% \mathrm{Cl} 1.172-7.426 ; p=0.022$ ) were demonstrated to be independently associated with poor SBP control (SBP > 130 $\mathrm{mmHg}$ ) using Logistic analysis.
\end{abstract}

Conclusions: The optimal cut-off value of SBP at discharge was $130 \mathrm{mmHg}$ which can be used to predict shortterm ARAE. Blood pressure in patients with hybrid operation and $\geq 2$ stents should be given more focus.

Keywords: Type B aortic dissection, Thoracic endovascular aortic repair, Optimal blood pressure, Aortic related adverse events

\section{Background}

Stanford type B aortic dissection (BAD) is a lifethreatening disease with high in-hospital and long-term follow-up mortality [1, 2]. Guidelines recommended tight blood pressure control for favorable outcomes but was still limited by certain cut-off level of systolic blood pressure (SBP), which was $120 \mathrm{mmHg}, 130 \mathrm{mmHg}, 135$ $\mathrm{mmHg}$ or $140 \mathrm{mmHg}$ [3-7]. For example, the newest European Society of Cardiology (ESC) guideline on the diagnosis and treatment of aortic diseases recommended that SBP should be maintained below $140 \mathrm{mmHg}$ in chronic conditions in the "Treatment options" section,

\footnotetext{
* Correspondence: xueruitan@163.com

${ }^{\dagger} \mathrm{Nan}$ Lu and Xiaojing Ma contributed equally to this work.

'Department of Cardiology, the First Affiliated Hospital of Shantou University Medical College, No. 57, Changping Road, Shantou, Guangdong 515041,

People's Republic of China

Full list of author information is available at the end of the article
}

whereas maintenance below $130 \mathrm{mmHg}$ in the "Longterm follow-up of aortic diseases" section was recommended [3]. Hypertension is a very important risk factor for aortic dissection. In principle, lower blood pressure is beneficial for patients with aortic dissection. However, too low blood pressure can cause signs or symptoms of ischaemia and complications of malperfusion, which would lead to failure or infarction of vital organs. In 2017, the American College of Cardiology (ACC) and American Heart Association (AHA) guideline for the management of high blood pressure in adults summarized that trials in patients with primary hypertension did not provide insight into the optimal blood pressure in patients with BAD [6]. Accordingly, evaluating the optimal cut-off value of SBP in BAD patients is very crucial and urgent. 
Medical therapy, open surgery and thoracic endovascular aortic repair (TEVAR) therapy are treatment strategies for BAD [3]. TEVAR is associated with better survival compared to medical therapy or open surgery [3]. It is increasingly becoming the first-line treatment for BAD patients $[8,9]$. Studies on blood pressure control of BAD were mostly after single medical therapy, rather than after TEVAR [3]. The International Registry of Acute Aortic Dissection (IRAD) study demonstrated that mortality after medical therapy was significantly increased in patients with BAD with refractory hypertension comparable to patients without refractory hypertension (35.6\% versus $1.5 \%$; $p=0.0003$ ) [10]. However, there was no significant difference after TEVAR therapy between patients with and without refractory hypertension (3.7\% versus $9.1 \%$; $p=0.50)$ [10]. Those results may suggest that patients with BAD after TEVAR are less likely to need strict requirement of tight blood pressure control like the patients after medical therapy.

We performed a study to define the optimal SBP value for Chinese BAD patients after TEVAR. The optimal cut-off value of SBP was verified by aortic related adverse events (ARAE) and then risk factors for poor SBP control were assessed.

\section{Methods}

\section{Study population}

A retrospective study was conducted on prospectively collected data of BAD patients undergoing TEVAR from January 2011 to April 2017 at Wuhan Asia Heart Hospital (Wuhan, China). Patients with medical history of aortic diseases, Marfan syndrome or other connective tissue diseases, bicuspid aortic valve, iatrogenic or traumatic dissection, syphilis and other inflammatory diseases of the aorta, cancer, pregnancy, severe renal or respiratory or cardiac insufficiency were excluded. Patients who experienced acute myocardial infarction, cerebrovascular disease (CVD) or major surgical procedures before or after 30 days of study enrolment were also excluded.

Data on demographic characteristics, medical history, presenting symptoms, biochemical and imaging findings, treatment strategies, medication use, blood pressure at discharge, in-hospital outcomes and follow-up outcomes were collected. Discharge blood pressure was the last recorded blood pressure obtained within $24 \mathrm{~h}$ before or at hospital discharge.

The study was performed in accordance with the ethical standards laid down in the 1964 Declaration of Helsinki and its later amendments. All procedures were approved by the Ethics Committee of Wuhan Asia Heart Hospital. Written informed consent were obtained from all participants.

\section{Treatment and follow-up}

All patients were treated with TEVAR and optimal antihypertensive medications. Each of the patients was measured by contrast-enhanced computed tomography (CT) before TEVAR procedure. TEVAR was performed according to the procedure described by Dake et al. [11] Successful TEVAR procedure was defined as technically successful placement of the stent graft at the intended target location without an endoleak [12]. Intravenous beta blockers and calcium channel blockers $(\mathrm{CCB})$ were administered alone or combination to reduce SBP to < $120 \mathrm{mmHg}$ as initial therapy in the intensive care unit. Intravenous medications were replaced by oral antihypertensive drugs including beta blockers, angiotensinconverting enzyme inhibitors (ACEI), angiotensin receptor blockers (ARB), CCB and diuretics, either alone or in combination. The decision when, whether and how to give oral antihypertensive medications was at the discretion of the treating physician according to current guidelines and the best clinical practice. Hypertension was defined as a self-reported diagnosis of hypertension, treatment with antihypertensive agents or having a clinical record of a blood pressure $\geq 140 / 90 \mathrm{mmHg}^{6}$. All subjects were classified into the acute group ( $\leq 14$ days), sub-acute group (14-90 days) and the chronic group (> 90 days), based on the time interval from the symptom onset date to the procedure date [3]. Body mass index (BMI) is equal to weight $(\mathrm{kg})$ divided by the square of height $\left(\mathrm{m}^{2}\right)$. Overweight was defined as a BMI between $25 \mathrm{~kg} / \mathrm{m}^{2}$ and $30 \mathrm{~kg} / \mathrm{m}^{2}$ and obesity as a BMI $\geq 30 \mathrm{~kg} / \mathrm{m}^{2}$ [13].

All patients were followed up by 3 clinical cardiologists. Data on symptoms, medications, laboratory measurements, electrocardiograms, echocardiograms and contrast-enhanced CT findings were collected through electronic data capture and telephone interviews. Thirty days and 90 days after the completion of TEVAR were designed to follow up. Ninety-day ARAE was used for statistical analysis in our study.

ARAE were defined as aortic related death, new dissection, progression of aortic dissection (aortic rupture, necessitating surgical procedure or TEVAR after discharge), malperfusion (bowel ischemia, renal ischemia and lower limb ischemia), paraplegia, major stroke or endoleaks [14-17].

\section{Statistical analysis}

One-Sample Kolmogorov-Smirnov test was used to evaluate the distribution of all variables. Age was a normal continuous variable and was presented as means \pm standard deviations. SBP, DBP, pulse pressureand heart rate at discharge were non-normal continuous variables and were presented as medians (quartile 1 to quartile 3 [Q1-Q3]). Sex, the classification of BMI, tobacco abuse, 
alcohol abuse, hypertension, DM, PAD, CVD, CAD, dyslipidemia, stage of BAD, operative procedure, number of stentand medications at discharge were categorical variables and they were shown as counts and percentages. Independent samples $t$-test, Mann-Whitney $U$ test and Chi-square test were used to compare the differences betweennormal continuous variables, non-normal continuous variables and categorical variables, respectively. SBP as a continuous variable predictor of the endpoint of 90-day ARAE was analyzed by receiver operator characteristic (ROC) curves. The optimal cut-off points of SBP to differentiate ARAE from non-ARAE outcomes were determined using Youden's index, which equally weighs sensitivity and specificity and maximizes the number of correctly classified patients. Overall ARAEfree probabilities were estimated using the Kaplan-Meier method and comparisons between groups were carried out using the log-rank test. The relationship between SBP at discharge and 90-day ARAE was assessed using univariate and multiple cox proportional hazard analysis. Logistic analysis was performed to identify independent risk factors for poor blood pressure control. Hazard rates (HR) and odds ratios (OR) were assessed with a 95\% confidence interval $(\mathrm{CI})$, and a two-tailed $p<0.05$ was considered statistically significant. All data analyses were performed using the statistical software Statistical Product and Service Solution (SPSS 19.0 for windows, Chicago, Illinois, USA).

\section{Results}

\section{Demographics}

There were 292 consecutive BAD patients who were initially treated with TEVAR in Wuhan Asia Heart Hospital. Among them, 1 patients who presented with other aortic lesions besides BAD, 1 with medical history of aortic diseases, 1 with Marfan syndrome, 1 with syphilitic aortic disease, 3 with iatrogenic or traumatic dissection, 5 with cancer, 3 with renal insufficiency, 2 patients who had CVD within 30 days of study enrolment, 4 patients who underwent surgical procedures within 30 days of study enrolment and 2 patients without follow-up records were excluded. Finally, 269 patients were enrolled.

All 269 patients completed 90 days of follow-up, and the unadjusted ARAE-free rates at 90-day was $95.1 \pm$ $1.3 \%$. The mean age of all patients was $55 \pm 10$ years, and $84.0 \%$ of the patients were males. Patient demographics, clinical characteristics, treatment, blood pressure and medications at discharge are outlined in Table 1.

\section{Selecting cut-off values of SBP to discriminate ARAE}

We constructed ROC curves of the SBP for the diagnosis of 90-day follow-up ARAE to find the optimal cut-off value with the highest Youden index. The optimal cutoff value of SBP at discharge for 90-day ARAE was
$131 \approx 130 \mathrm{mmHg}$. Subsequently, all the patients were divided into $\mathrm{SBP} \leq 130 \mathrm{mmHg}$ group and $\mathrm{SBP}>130 \mathrm{mmHg}$ group when the 90-day outcomes were analysed.

\section{Risk factors forARAE}

Cumulative ARAE-free rate in all patients was $95.1 \pm$ $1.3 \%$ at 90 -day follow-up. The probability of 90-day ARAE-free as categorized by SBP using Kaplan-Meier analysis showed significant differences among the two groups $\quad(\mathrm{SBP} \leq 130 \mathrm{mmHg}$ group vs. $\mathrm{SBP}>130 \mathrm{mmHg}$ group, $p=0.012$ ), as shown in Fig. 1. Multivariate Cox analysis was performed. SBP at discharge (HR 3.780; 95\% CI $1.236-11.556 ; p=0.020$ ) was the only significant predictor of 90-dayARAE.

\section{Risk factors for poor SBP control}

All patients were divided into 2 groups according to the significant cut-off value of SBP at discharge: SBP $\leq 130$ $\mathrm{mmHg}$ group and $\mathrm{SBP}>130 \mathrm{mmHg}$ group. Table 1 shows the details of patient characteristics categorized by SBP group. BMI, CVD, stage of BAD, operative procedures and number of stents were significantly different between the two groups. Hybrid operation (OR 2.046; 95\%CI 1.015-4.122; $p=0.045)$ and insertion of $\geq 2$ stents (OR 2.950; 95\%CI 1.172-7.426; $p=0.022$ ) were demonstrated to be independently associated with poor SBP control (SBP > $130 \mathrm{mmHg}$ ) by Logistic analysis (Table 2).

\section{Discussion}

In the present, we examined the optimal cut-off value of SBP at discharge and the risk factors for poor blood pressure control. The main findings showed that lowering SBP at discharge to a target goal of $\leq 130 \mathrm{mmHg}$, compared with $>130 \mathrm{mmHg}$, resulted in significantly lower rates of 90-day ARAE. Logistic analysis demonstrated that significant predictors of poor blood pressure include hybrid operations and insertion of $\geq 2$ stents.

The results presented herein are consistent with hemodynamic mechanismsin patients with $\mathrm{BAD}$ to stabilize the aortic wall and prevent ARAE [3]. A much higher blood pressure may further increase the risk of ARAE as Delsartet al. demonstrated that an SBP more than $130 \mathrm{mmHg}$ was associated with more aortic enlargement, which has already been described as a risk factor of ARAE in patients with BAD [18]. While significantly lowering blood pressure can possibly compromise organ perfusion, and increase 30-day mortality in patients with ruptured abdominal aortic aneurysm, particularly in the older patient with other cardiovascular diseases and high cardiovascular resistance [19].

The blood pressure target for patients with type A aortic dissection and BAD should be different. Type A dissections have the worst prognosis with an overall inhospital mortality of $30 \%$, whereas BAD tends to have a 
Table 1 Baseline characteristics of patients with type B aortic dissection after TEVAR

\begin{tabular}{|c|c|c|c|c|}
\hline & $\begin{array}{l}\text { Overall } \\
n=269\end{array}$ & $\begin{array}{l}\text { SBP } \leq 130 \mathrm{mmHg} \text { group } \\
n=229\end{array}$ & $\begin{array}{l}\text { SBP > } 130 \mathrm{mmHg} \text { group } \\
n=40\end{array}$ & $p$ \\
\hline Males, n (\%) & $226(84.0)$ & $190(83.0)$ & $36(90.0)$ & 0.263 \\
\hline Age (year) & $55.5 \pm 9.9$ & $55.5 \pm 9.9$ & $55.9 \pm 9.8$ & 0.818 \\
\hline BMI, n (\%) & & & & 0.048 \\
\hline Normal & $148(55.0)$ & $127(55.5)$ & $21(52.5)$ & \\
\hline Overweight & $108(40.2)$ & $94(41.0)$ & $14(35.0)$ & \\
\hline Obesity & $13(4.8)$ & $8(3.5)$ & $5(12.5)$ & \\
\hline Tobacco abuse, n (\%) & $177(65.8)$ & $150(65.5)$ & $27(67.5)$ & 0.806 \\
\hline Alcohol abuse, n (\%) & $62(23.0)$ & $52(22.7)$ & $10(25.0)$ & 0.751 \\
\hline Hypertension, n (\%) & $240(89.2)$ & $203(88.6)$ & $37(92.5)$ & 0.468 \\
\hline $\mathrm{DM}, \mathrm{n}(\%)$ & $26(9.7)$ & $22(9.6)$ & $4(10.0)$ & 0.938 \\
\hline PAD, n (\%) & $124(46.1)$ & $105(45.9)$ & $19(47.5)$ & 0.847 \\
\hline CVD, n (\%) & $100(37.2)$ & $79(34.5)$ & $21(52.5)$ & 0.030 \\
\hline CAD, n (\%) & $54(20.1)$ & $42(18.3)$ & $12(30.0)$ & 0.089 \\
\hline Dyslipidemia, n (\%) & $190(70.6)$ & $159(69.4)$ & $31(77.5)$ & 0.301 \\
\hline Stage of BAD, n (\%) & & & & 0.020 \\
\hline Acute & $163(60.6)$ & $143(62.5)$ & $20(50.0)$ & \\
\hline Sub-acute & $60(22.3)$ & $53(23.1)$ & $7(17.5)$ & \\
\hline Chronic & $46(17.1)$ & $33(14.4)$ & $13(32.5)$ & \\
\hline Operative procedure, n (\%) & & & & 0.041 \\
\hline TEVAR & $191(71.0)$ & $168(73.4)$ & $23(57.5)$ & \\
\hline Hybrid operation & $78(29.0)$ & $61(26.6)$ & $17(42.5)$ & \\
\hline Number of stent, n (\%) & & & & 0.017 \\
\hline 1 & $243(90.3)$ & $211(92.1)$ & $32(80.0)$ & \\
\hline$\geq 2$ & $26(9.7)$ & $18(7.9)$ & $8(20.0)$ & \\
\hline $\mathrm{SBP}$ at discharge, $\mathrm{mm} \mathrm{Hg}$ & $120(115-130)$ & $120(114-125)$ & $140(135-140)$ & $<0.001$ \\
\hline $\mathrm{DBP}$ at discharge, $\mathrm{mm} \mathrm{Hg}$ & $70(68-75)$ & $70(68-70)$ & $76(70-80)$ & $<0.001$ \\
\hline Pulse pressure at discharge, $\mathrm{mm} \mathrm{Hg}$ & $50(64-72)$ & $50(42-54)$ & $61(58-70)$ & $<0.001$ \\
\hline Heart rate at discharge, beats per minute & $68(64-72)$ & $68(64-72)$ & $70(63-74)$ & 0.255 \\
\hline \multicolumn{5}{|l|}{ Medications at discharge, n (\%) } \\
\hline ACEI/ARB & $242(90.0)$ & $205(89.5)$ & $37(92.5)$ & 0.563 \\
\hline $\mathrm{CCB}$ & $240(89.2)$ & $205(89.5)$ & $35(87.5)$ & 0.704 \\
\hline Beta blocker & $260(96.7)$ & $220(96.1)$ & $40(100.0)$ & 0.202 \\
\hline Diuretic & $72(26.8)$ & $59(25.8)$ & $13(32.5)$ & 0.375 \\
\hline Statin & $206(76.6)$ & $177(77.3)$ & $29(72.5)$ & 0.509 \\
\hline
\end{tabular}

$B M I$ body mass index, $D M$ diabetes mellitus, $P A D$ peripheral arterial disease, $C V D$ cerebrovascular diseases, $C A D$ coronary artery disease, $B A D$ type $B$ aortic dissection, GFR glomerular filtration rate, TEVAR thoracic endovascular aortic repair, SBP systolic blood pressure, DBP diastolic blood pressure, $A C E I$ angiotensinconverting enzyme inhibitors, $A R B$ angiotensin receptor blockers, $C C B$ calcium-channel blockers

better prognosis than type A dissections, having an overall in-hospital mortality rate of $13 \%$ [20]. A recent study assessed the effect of blood pressure on 260-month outcomes following repair of type A acute dissection [21]. Patients with a SBP $<120 \mathrm{mmHg}$ had a reduced risk of reoperation compared with those having a SBP $120-140 \mathrm{mmHg}$ or $>140 \mathrm{mmHg}$ by Kaplan-Meier analysis. In our study, $130 \mathrm{mmHg}$ was demonstrated to be the target SBP for BAD patients. This value is slightly higher than $120 \mathrm{mmHg}$, which was derived from the above study of type A aortic dissection patients. Therefore, the blood pressure target of 130 $\mathrm{mmHg}$ is reasonable for BAD patients. However, the detailed difference of blood pressure control between type A aortic dissection and BAD need to be investigated in a future study. 


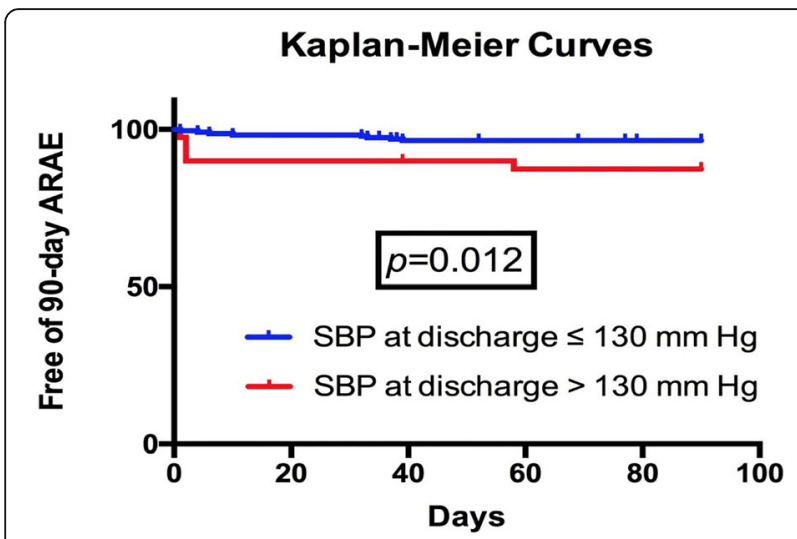

Fig. 1 Free of ARAE of patients divided by systolic blood pressure at discharge. Kaplan-Meier calculation of freedom from development of ARAE in BAD patients after TEVAR by grouping with systolic blood pressure at discharge. (ARAE: aortic-related adverse events; BAD: type B aortic dissection; TEVAR: thoracic endovascular aortic repair)

In general, different treatments, including medical, TEVAR and surgery, are suitable for BAD patients with different serious conditions. For BAD patients with different therapies, the standard of decrease of blood pressure possibly shall vary. Theoretically, the cut-off value of SBP is more likely to need a lower level in BAD patients treated with simple medical than that after TEVAR, as the aortas of the latter are protected by stents. After the specific treatment plan, the level of blood pressure control should be regulated for BAD patients treated with variable surgery. In brief, multicenter, large sample studies are needed to clarify these problems in the future.

In this study, we recorded blood pressure at discharge instead of at follow-up. We consider that blood pressure at discharge is inconsistence with the one recorded at follow-up, indicating different implication. Blood pressure at follow-up indicates the management of blood pressure among a period of time after discharge, while the one at discharge demonstrates a better state of blood pressure in BAD patients after regular management by clinicians in inpatient department. Recent years, several studies have confirmed that SBP at discharge was a

Table 2 Multiple logistic analysis of risk factors for poor blood pressure control

\begin{tabular}{llll}
\hline \multicolumn{1}{c}{ OR } & $95 \% \mathrm{Cl}$ & $p$ value \\
\hline $\begin{array}{l}\text { Operative procedure, } \mathrm{n}(\%) \\
\text { TEVAR }\end{array}$ & Reference & & \\
Hybrid operation & 2.046 & $1.015-4.122$ & 0.045 \\
Number of stent, $\mathrm{n}(\%)$ & & & \\
1 & Reference & & 0.022 \\
$\geq 2$ & 2.950 & $1.172-7.426$ & \\
\hline TEVAR thoracic endovascular aortic repair & &
\end{tabular}

significant predictor for long-term outcomes [22, 23]. Even though, further studies are needed to determine the association between blood pressure at discharge and long-term follow-up and to define an optimal long-term follow-up blood pressure range for BAD patients after TEVAR.

CVD was a risk factor of ARAE in BAD patients after TEVAR in the present study. Based on previous studies, CVD patients were older, more often had hypertension and atherosclerosis, and presented more frequently with symptoms such as syncope, hypotension, shock and pulse deficit [24]. These factors were all associated with an increased prevalence of morbidity and other complications in BAD patients [3]. Therefore, aortic dissection patients with CVD may have a high predicted mortality, and this association was also demonstrated in a previous study [25].

Hybrid operation and insertion of $\geq 2$ stents were risk factors for poor blood pressure. Hybrid operations were performed in patients involving the distal aortic arch. BAD involving the distal aortic arch are characterized by a high risk of rapidly expanding false lumens which may result in increments of vascular resistance and then effect blood pressure management. Patients with $\geq 2$ stents presented with a large range of dissection, which mainly involved renal arteries, as described by a previous study [26]. A study further demonstrated that patients with renal artery dissections presented with severe hypertension [27]. Consequently, patients with $\geq 2$ stents may have a greater risk of high pressure blood.

Antihypertensive medications play a main role in the management of BAD. Current practice in the treatment of chronic BAD is the use of beta-blockers as first-line therapy to reduce the force of left ventricular ejection, decrease aortic wall stress and improve survival [6]. ESC 2014 guidelines on the diagnosis and treatment of aortic dissection regarded beta-blockers as initial antihypertensive medications [3]. However, our data failed to show the benefit of the routine use of beta-blockers. Because beta-blockers were prescribed to $96.7 \%$ of patients in our study and the statistical analysis were limited to demonstrated significant results. Other antihypertensive medications, such as CCB, ACEI and ARB have been suggested for the medical therapy of BAD. However, these suggested antihypertensive medications did not improve survival in a series of patients with type A and type B aortic dissections [28]. Our results are consistent with these previous findings.

\section{Limitations}

There are several limitations to the present study. First, the monitor of ambulatory blood pressure and blood pressure variability providng insight into overall blood pressure control for outpatient during follow-up were 
not performed. Second, the present study is a singlecenter study and multi-center studies in type BAD are required in the future. Finally, the choice of antihypertensive medications was leftat the physician's discretion and subject to potential selection bias.

\section{Conclusions}

The optimal cut-off value of SBP at discharge was 130 mmHg which can be used to predict 90-day ARAE. It may be difficult to control SBP at discharge for patients with hybrid operation and $\geq 2$ stents. Further studies on blood pressure might provide new preventive and therapeutic strategies for aortic dissection.

\begin{abstract}
Abbreviations
ACC: The American college of cardiology; ACEl: Angiotensin-converting enzyme inhibitors; AHA: The American heart association; ARAE: Aortic related adverse events; ARB: Angiotensin receptor blockers; BAD: Stanford type B aortic dissection; BMl: Body mass index; CCB: Calcium channel blockers; Cl: Confidence interval; CT: Computed tomography; CVD: Cerebrovascular disease; ESC: European society of cardiology; HR: Hazard rates; IRAD: The international registry of acute aortic dissection; OR: Odds ratios; ROC: Receiver operator characteristic; SBP: Systolic blood pressure; TEVAR: Thoracic endovascular aortic repair
\end{abstract}

\section{Acknowledgements}

Authors would like to show our thankfulness acknowledge to Dr. Li Wang for her acquisition of data.

\section{Authors' contributions}

$\mathrm{NL}$ contributed to the conception, design, data acquisition, data analysis and writing. XJM and XRT contributed to conception and design. TX, ZQH, and QFX, contributed to acquisition of data. BYX contributed to the analysis and interpretation of data. All authors contributed to the revision of the manuscript. XRT is the guarantor of the paper, taking responsibility for the integrity of the work as a whole, from incepton to published article. All authors reviewed this manuscript and approved the final version to be published. Agreement to be accountable for all aspects of the work was acquired from all authors.

\section{Funding}

The study was supported by the National Natural Science Foundation of China (No.81473063) and Guangdong Science and Technology Department (No.2014A020212559). The funding bodies had no role in the design of the study and collection, analysis, and interpretation of data and in writing of the manuscript.

\section{Availability of data and materials}

Raw data supporting the obtained results are available at the corresponding author.

\section{Ethics approval and consent to participate}

All procedures were approved by the Ethics Committee of Wuhan Asia Heart Hospital. Written informed consent were obtained from all participants.

\section{Consent for publication}

Not applicable.

\section{Competing interests}

The authors declare that they have no conflict of interest.

\section{Author details}

'Department of Cardiology, the First Affiliated Hospital of Shantou University Medical College, No. 57, Changping Road, Shantou, Guangdong 515041, People's Republic of China. ${ }^{2}$ Image Center, Wuhan Asia Heart Hospital, Wuhan, Hubei 430000, People's Republic of China.
Received: 18 February 2019 Accepted: 17 May 2019

Published online: 27 May 2019

\section{References}

1. Tsai TT, Fattori R, Trimarchi S, Isselbacher E, Myrmel T, Evangelista A, et al. Long-term survival in patients presenting with type B acute aortic dissection: insights from the international registry of acute aortic dissection. Circulation. 2006;114(21):2226-31.

2. Fattori R, Montgomery D, Lovato L, Kische S, Di Eusanio M, Ince $H$, et al. Survival after endovascular therapy in patients with type B aortic dissection. a report from the International Registry of Acute Aortic Dissection (IRAD) JACC Cardiovasc Interv. 2013;6(8):876-82.

3. Erbel R, Aboyans V, Boileau C, Bossone E, Di Bartolomeo R, Eggebrecht H, et al. 2014 ESC guidelines on the diagnosis and treatment of aortic diseases. Kardiol Pol. 2014;72(12):1169-252.

4. Erbel R, Alfonso F, Boileau C, Dirsch O, Eber B, Haverich A, et al. Diagnosis and management of aortic dissection. Eur Heart J. 2001;22(18):1642-81.

5. James PA, Oparil S, Carter BL, Cushman WC, Dennison-Himmelfarb C, Handler J, et al. 2014 evidence-based guideline for the management of high blood pressure in adults: report from the panel members appointed to the eighth joint National Committee (JNC 8). Jama. 2014;311(5):507-20.

6. Whelton PK, Carey RM, Aronow WS, Casey DE Jr, Collins KJ, Dennison Himmelfarb C, et al. 2017ACC/AHA/AAPA/ABC/ACPM/AGS/APhA/ASH/ASPC/ NMA/PCNA Guideline for the Prevention, Detection, Evaluation, and Management of High Blood Pressure in Adults: A Report of the American College of Cardiology/American Heart Association Task Force on Clinical Practice Guidelines. J Am College Cardiology. 2017.

7. Guidelines for diagnosis and treatment of aortic aneurysm and aortic dissection (JCS 2011): digest version. Circulation journal : official journal of the Japanese Circulation Society. 2013;77(3):789-828.

8. Kische S, Ehrlich MP, Nienaber CA, Rousseau H, Heijmen R, Piquet P, et al. Endovascular treatment of acute and chronic aortic dissection: midterm results from the talent thoracic retrospective registry. J Thorac Cardiovasc Surg. 2009;138(1):115-24.

9. Fattori R, Tsai TT, Myrmel T, Evangelista A, Cooper JV, Trimarchi S, et al. Complicated acute type B dissection: is surgery still the best option? a report from the International Registry of Acute Aortic Dissection JACC Cardiovasc Interv. 2008;1 (4):395-402.

10. Trimarchi S, Eagle KA, Nienaber CA, Pyeritz RE, Jonker FH, Suzuki T, et al. Importance of refractory pain and hypertension in acute type B aortic dissection: insights from the international registry of acute aortic dissection (IRAD). Circulation. 2010;122(13):1283-9.

11. Dake MD, Kato N, Mitchell RS, Semba CP, Razavi MK, Shimono T, et al. Endovascular stent-graft placement for the treatment of acute aortic dissection. N Engl J Med. 1999;340(20):1546-52.

12. Hiratzka LF, Bakris GL, Beckman JA, Bersin RM, Carr VF, Casey DE Jr, et al. 2010 ACCF/AHA/AATS/ACR/ASA/SCA/SCAI/SIR/STS/SVM guidelines for the diagnosis and management of patients with thoracic aortic disease: a report of the American College of Cardiology Foundation/American Heart Association task force on practice guidelines, American Association for Thoracic Surgery, American College of Radiology, American Stroke Association, Society of Cardiovascular Anesthesiologists, Society for Cardiovascular Angiography and Interventions, Society of Interventional Radiology, Society of Thoracic Surgeons, and Society for Vascular Medicine. Circulation. 2010;121(13):e266-369.

13. Catapano AL, Graham I, De Backer G, Wiklund O, Chapman MJ, Drexel H, et al. 2016 ESC/EAS guidelines for the Management of Dyslipidaemias. Kardiol Pol. 2016;74(11):1234-318.

14. Qin YL, Deng G, Li TX, Wang W, Teng GJ. Treatment of acute type-B aortic dissection. thoracic endovascular aortic repair or medical management alone? JACC Cardiovasc Interv. 2013;6(2):185-91.

15. Brunkwall J, Lammer J, Verhoeven E, Taylor P. ADSORB: a study on the efficacy of endovascular grafting in uncomplicated acute dissection of the descending aorta. Eur J Vasc Endovasc Surg. 2012;44(1):31-6.

16. Delsart P, Ledieu GJ, Ramdane N, Sobocinski JP, Clough RE, Azzaoui RO, et al. Impact of the Management of Type B Aortic Dissection on the long-term blood pressure. Am J Cardiol. 2017;120(3):484-8.

17. Lu N, He Z, Xu T, Chen X, Chen X, Ma X, et al. Association of Thyroid Function with early/mid-term aorta-related adverse events and readmissions after thoracic endovascular aortic repair. Sci Rep. 2017;7(1):14730. 
18. Delsart P, Midulla M, Sobocinski J, Achere C, Haulon S, Claisse G, et al. Predictors of poor blood pressure control assessed by 24 hour monitoring in patients with type B acute aortic dissection. Vasc Health Risk Manag. 2012;8:23-30.

19. Powell JT, Hinchliffe RJ, Thompson MM, Sweeting MJ, Ashleigh R, Bell R, et al. Observations from the IMPROVE trial concerning the clinical care of patients with ruptured abdominal aortic aneurysm. Br J Surg. 2014;101(3): 216-24; discussion 24.

20. Chan KK, Lai P, Wright JM. First-line beta-blockers versus other antihypertensive medications for chronic type B aortic dissection. The Cochrane database of systematic reviews. 2014;(2):Cd010426.

21. Melby SJ, Zierer A, Damiano RJ Jr, Moon MR. Importance of blood pressure control after repair of acute type a aortic dissection: 25-year follow-up in 252 patients. J Clin Hypertens (Greenwich). 2013;15(1):63-8.

22. Nassif ME, Tibrewala A, Raymer DS, Andruska A, Novak E, Vader JM, et al. Systolic blood pressure on discharge after left ventricular assist device insertion is associated with subsequent stroke. The Journal of heart and lung transplantation : the official publication of the International Society for Heart Transplantation. 2015;34(4):503-8.

23. Fujishima S, Takiguchi T, Ibaraki A, Shimazoe H, Hagiwara R, Koyanagi Y, et al. Relationship among multifaceted factors including blood pressure at discharge and long-term clinical outcome in patients with cardiovascular diseases. Clinical and experimental hypertension (New York, NY : 1993). 2016;38(8):725-32.

24. Yaghi S, Willey JZ, Cucchiara B, Goldstein JN, Gonzales NR, Khatri P, et al. Treatment and outcome of hemorrhagic transformation after intravenous Alteplase in acute ischemic stroke: a scientific statement for healthcare professionals from the American Heart Association/American Stroke Association. Stroke. 2017;48(12):e343-e61.

25. Bossone E, Corteville DC, Harris KM, Suzuki T, Fattori R, Hutchison S, et al. Stroke and outcomes in patients with acute type a aortic dissection. Circulation. 2013;128(11 Suppl 1):S175-9.

26. Fattori R, Cao P, De Rango P, Czerny M, Evangelista A, Nienaber C, et al. Interdisciplinary expert consensus document on management of type B aortic dissection. J Am Coll Cardiol. 2013;61(16):1661-78.

27. Pellerin O, Garcon P, Beyssen B, Raynaud A, Rossignol P, Jacquot C, et al. Spontaneous renal artery dissection: long-term outcomes after endovascular stent placement. J vascular Int radiology : JVIR. 2009;20(8):1024-30.

28. Suzuki T, Isselbacher EM, Nienaber CA, Pyeritz RE, Eagle KA, Tsai TT, et al. Type-selective benefits of medications in treatment of acute aortic dissection (from the international registry of acute aortic dissection [IRAD]). Am J Cardiol. 2012;109(1):122-7.

\section{Publisher's Note}

Springer Nature remains neutral with regard to jurisdictional claims in published maps and institutional affiliations.

Ready to submit your research? Choose BMC and benefit from:

- fast, convenient online submission

- thorough peer review by experienced researchers in your field

- rapid publication on acceptance

- support for research data, including large and complex data types

- gold Open Access which fosters wider collaboration and increased citations

- maximum visibility for your research: over $100 \mathrm{M}$ website views per year

At BMC, research is always in progress.

Learn more biomedcentral.com/submissions 